\title{
Problemas de la traducción de textos de contenido jurídico: búsqueda de los equivalentes más apropiados
}

\section{(Problems of translation of texts of legal content: searching the most appropriate equivalent)}

\author{
Jana PešKová \\ jn.peskova@seznam.cz \\ Universidad de Bohemia del Sur (República Checa)
}

\begin{abstract}
Fecha de recepción: 24 de agosto de 2015
Fecha de aceptación: 2 de octubre de 2015

Resumen: La autora pretende aportar en el constante debate relacionado con el problema de la búsqueda de nociones equivalentes en textos de contenido jurídico. Para ello, centra su interés en analizar un par de conceptos jurídicos checos y españoles con el fin de demostrar y recalcar que la traducción de los textos de contenido jurídico entre dos lenguas tipológicamente -y culturalmente- diferentes (como por ejemplo el español y el checo) a menudo conlleva aparejada la necesidad de tomar un abanico muy variado de decisiones por parte del traductor. De este modo, uno de los objetivos de la ponencia sería reflexionar acerca de maneras varias y diferentes de la traducción de las unidades léxicas culturalmente marcadas y, también, opinar acerca de los convenientes e inconvenientes de algunas técnicas empleadas por los traductores en textos de diferente grado de especialidad.
\end{abstract}

Palabras clave: Traducción jurídica, Anisomorfismo, Equivalencia, Terminología jurídica.

Abstract: The author tries to contribute to the debate regarding the problem of finding equivalents in legal texts. To do this, it focuses its interest in analyzing a pair of Czech and Spanish legal concepts, in order to demonstrate and emphasize that the translation of texts of legal content between two typologically and culturally different languages (such as the Spanish and Czech) often carries with the need for a diverse range of decisions by the translator. Thus, one objective of the paper would reflect on several different ways of translating culturally marked lexical units and also comment about the ups and downs of some techniques used by different translators of texts of different degree of specialization. 
Key words: Legal Translation, Anisomorphism, Equivalence, Legal Terminology.

\section{INTRODUCCIÓN}

Es bien sabido que la traducción de textos de contenido jurídico esconde muchas dificultades para los traductores. El denominador común del conjunto de los problemas de la traducción jurídica estriba en el hecho de que (i) los conceptos jurídicos no se corresponden exactamente en el texto original y su traducción, dada la diferencia cultural y jurídica entre ambos, y (ii) que, dadas las diferentes convenciones textuales (o genéricas, en palabras de Alcaraz Varó), vinculadas a ese sector del lenguaje especializado, a menudo es bastante difícil y complicado lograr mantener la fidelidad estilística deseada sin extranjerizar el texto meta, introduciendo en él elementos idiosincrásicos del texto traducido. De lo que acabamos de exponer, hemos querido adelantar que, para nosotros, un texto especializado, en nuestro caso texto de contenido jurídico, es un resultado de la interacción mutua de lo que llamamos componente constante y componente potencial del texto especializado:

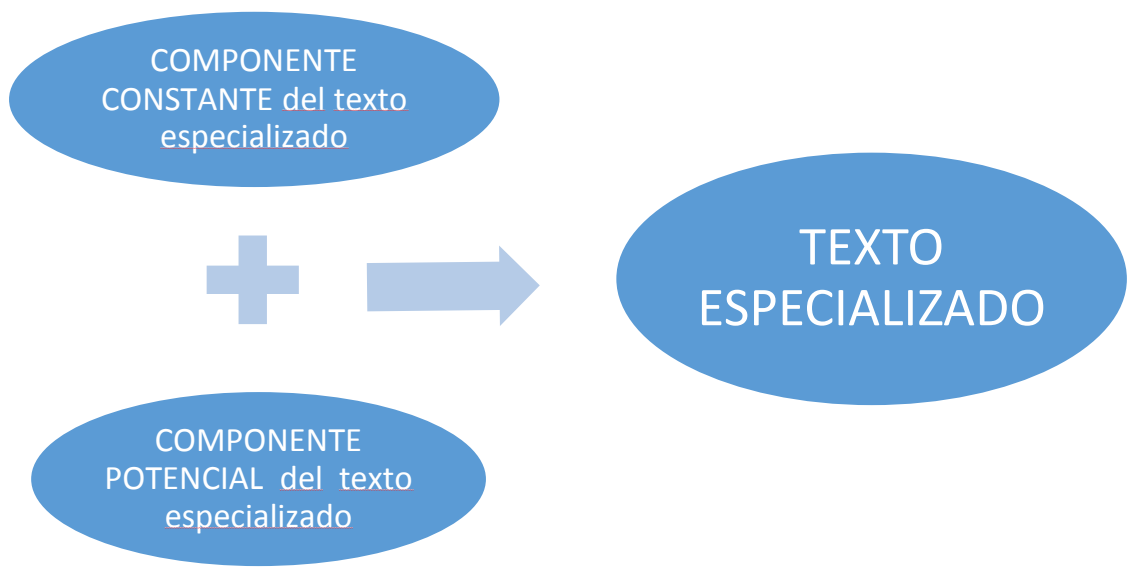

Denominamos como el componente constante a las unidades léxicas que poseen un significado específico y delimitado en un ámbito profesional determinado, sin los cuales un texto especializado es difícilmente constituible (términos especializados o semiespecializados). Por su parte, denominamos el componente potencial a los elementos estilísticamente 
marcados de nivel morfosintáctico y/o lexical, cuyo uso en el lenguaje común es limitado, aunque no imposible. Veamos los siguientes ejemplos concretos del componente potencial en los textos de contenido jurídico redactados en la lengua española: a) nivel morfosintáctico: "el que cometiere"(expresión estilísticamente marcada) frente a "el que cometa"(estilísticamente neutral); preferencia de imperativos a la hora de expresar mandatos "notifíquese"(expresión estilísticamente marcada) frente a: "hay que notificar"(estilísticamente neutral), la preferencia de las construcciones verbonominales como "efectuar / formalizar el pago" (expresiones estilísticamente marcadas)ante predicados simples como "pagar" (estilísticamente neutral); b) nivel lexical: uso de ciertas locuciones prepositivas como "de conformidad con" (expresión estilísticamente marcada) frente a las preposiciones simples y estilísticamente neutrales como "según", preferencia de ciertos verbos auxiliares como "efectuar/formalizar el pago" frente a verbos auxiliares estilísticamente neutrales como "hacer el pago".

Para que todo esto quede aún más claro tomaremos a continuación una cita de Dubský, en cuyos fundamentos teóricos estamos basando el esquema precedente:

\begin{abstract}
Llamamos componente potencial del estilo funcional especializado a los medios de expresión tomados de la lengua común, o utilizados en otros estilos funcionales cuyo uso no es indispensable en el estilo funcional en cuestión, sino solamente posible, potencial (Dubský, 1984: 29).
\end{abstract}

Desde el punto de vista de la traducción de un texto especializado (jurídico) es indiscutible que la distribución de lo que hemos llamado como el componente constante (terminológico) y el componente potencial (no terminológico) debería ser reflejada por el traductor, utilizando para ello una variedad de diversos procedimientos (o técnicas) de traducción. Los traductores deben de ser competentes para reconocer esos elementos en el texto original y para encontrar soluciones adecuadas para su correcta traslación de una a otra lengua. La distribución del componente constante y del componente potencial es, sin embargo, muy desproporcional en los textos especializados de contenido jurídico, y no equilibrada. Por un lado, hay textos (a continuación indicados como tipo A) como por ejemplo comisiones rogatorias, sentencias u otros escritos jurídicos, procedentes ante todo del derecho nacional, en los cuales la frecuencia de ambos componentes es relativamente muy alta. Eso se nota en el alto uso de terminología especializada y en la alta frecuencia de las estructuras morfosintácticas y lexicales como las que hemos comentado arriba. Por otro lado, hay textos jurídicos (a continuación indicados como tipo B) donde 
prevalece más bien uno de esos componentes contra el otro: es el caso de, por ejemplo, los textos legislativos del derecho comunitario en Eur-Lex, etc. donde podemos notar cierta pobreza en el uso de las estructuras idiosincrásicas del texto jurídico nacional (componente potencial), a pesar de tratarse de textos de contenido jurídico. Veamos los siguientes ejemplos:

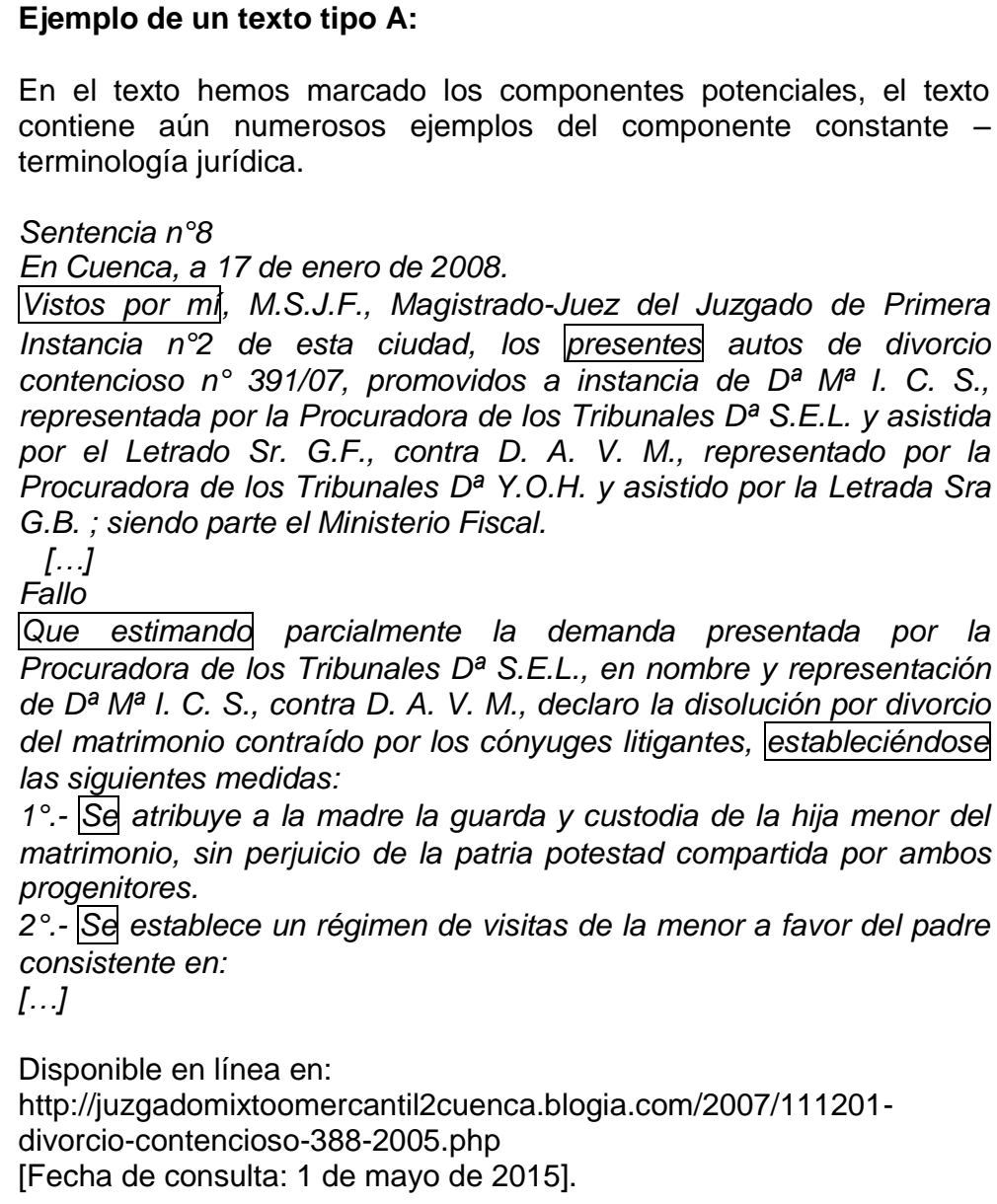

$1^{\circ}$.- Se atribuye a la madre la guarda y custodia de la hija menor del matrimonio, sin perjuicio de la patria potestad compartida por ambos progenitores.

$2^{\circ}$.- Se establece un régimen de visitas de la menor a favor del padre consistente en:

$[\ldots]$

Disponible en línea en:

http://juzgadomixtoomercantil2cuenca.blogia.com/2007/111201-

divorcio-contencioso-388-2005.php

[Fecha de consulta: 1 de mayo de 2015]. 


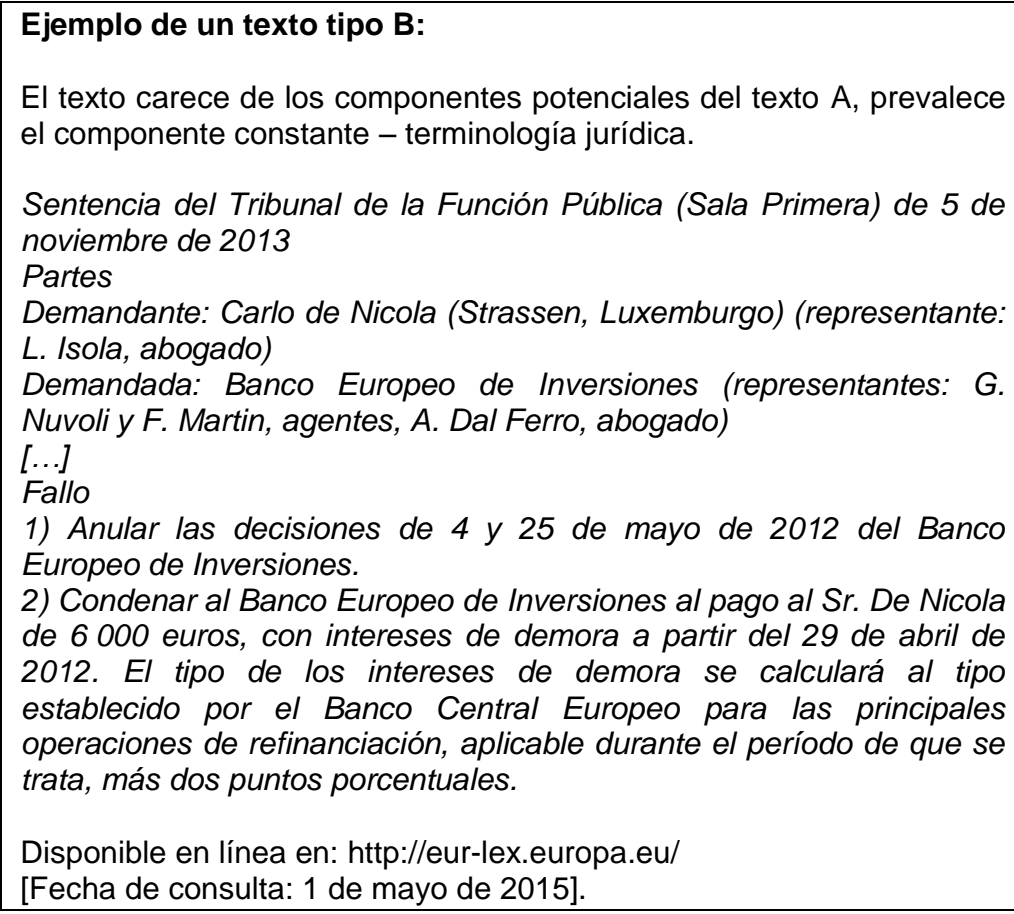

Aquí en este punto, también, pasamos a explicar brevemente por qué utilizamos en el título del presente artículo el concepto de "textos de contenido jurídico". La explicación es muy simple: como podemos ver, y como, naturalmente, todos sabemos (o intuimos), la tipología de los textos jurídicos es muy variada: desde los textos sumamente especializados destinados a los expertos en materia jurídica hasta textos divulgativos, destinados principalmente al público no experto, lo cual, según mi opinión hace que aparezca más de una solución traductológica de los conceptos jurídicos, tal y como podemos evidenciar a continuación.

Ahora bien, de conformidad con lo que acabamos de exponer, intentaremos analizar brevemente algunas de las posibles soluciones que los traductores pueden adoptar a la hora de enfrentarse con la traducción de ese tipo de textos, limitándonos por cuestiones de espacio a los problemas que conlleva la traducción del componte constante (terminológico) de los textos de contenido jurídico. 


\section{Problemas deRIVAdOS DE LA TRADUCCIÓN DE LA TERMINOLOGía JURíDICA}

Como ya hemos mencionado, la traducción del componente constante (terminológico) de un texto especializado entraña varios problemas. Entre los clásicos destaca el problema relacionado con la búsqueda de nociones equivalentes que a menudo no se corresponden en el texto original y su traducción, dado que no coinciden exactamente los sistemas jurídicos a los que pertenecen los países en cuestión. Generalmente, se admite que la equivalencia entre los conceptos jurídicos traducidos puede ser total, parcial o nula. El grado de las "asimetrías terminológicas" o "lagunas terminológicas" (anisomorfismo) entre dos lenguas se supedita a factores muy variados, entre los cuales destacamos: la proximidad de las culturas y de los sistemas jurídicos en cuestión, el grado de especialidad del texto traducido y el género textual. Pasemos ahora a comentar brevemente ambos:

\subsection{La realidad extralingüística muy diferente - equivalencia nula}

Es evidente que cuanto más lejanas, sociocultural e incluso tipológicamente, es la lengua del texto original y la lengua de su traducción, tanto más complejo y variado será el grado de las asimetrías terminológicas, lo cual conllevará aparejada una clara y lógica necesidad de buscar entre las posibles soluciones la que más convenga a las finalidades y el skopos del texto objeto de traducción. Muchas de las diferencias terminológicas son, a nuestro modo de ver, el resultado de que las realidades extralingüísticas de la lengua del original (LO) y lengua meta (LM) son contempladas desde diferentes perspectivas por parte de sus hablantes.

Para dar un ejemplo del lenguaje jurídico observemos el caso de las diferentes traducciones de los órganos del sistema judicial español, en los cuales, igual como en otros casos, se notan reflejados el contenido de su actividad, sus competencias y la distribución geográfica del cada país. Ya son clásicos los ejemplos de diferentes técnicas de traducción que vienen empleándose. Me limitaré a demostrar aquí una breve lista de diferentes técnicas que hemos encontrado en el corpus lingüístico Intercorp para "Audiencia Nacional" 


\begin{tabular}{|c|c|c|c|}
\hline & InterCorp v7 - Spanish & & InterCorp v7 - Czech \\
\hline _ EUROPARL & $\begin{array}{l}\text { 〈p〉 Ésta es la situación en la que viven diez personas, la } \\
\text { mayoria de ellas periodistas, desde que, en febrero de 2003, } \\
\text { la Audiencia Nacional española decidiese, sin juicio previo, } \\
\text { cerrar el periódico Egunkaria. }\end{array}$ & EUROPARL & $\begin{array}{l}\text { 〈p〉 Jedná se o deset osob, většina z nich jsou novinári, } \\
\text { kterii se v této situaci nacházeji od února } 2003 \text {, kdy } \\
\text { španělský nejyyšši soud rozhodl o zrušeni novin Egunkaria - } \\
\text { bez dalš́ho slyšení. }\end{array}$ \\
\hline _.PRESSEUROP & $\begin{array}{l}\text { Sin embargo, su trayectoria le ha convertido en " un personaje } \\
\text { parecido a un justiciero de alcance internacional "ya que, } \\
\text { desde su asiento de la Audiencia Nacional, ha exportado su } \\
\text { prestigio fuera de las fronteras españolas con casos como el } \\
\text { de Pinochet, un intento de procesar a Berlusconi y la petición } \\
\text { de detención de Osama Bin Laden. }\end{array}$ & PRESSEUROP & 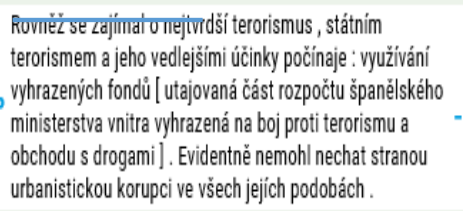 \\
\hline ב EUROPARL & $\begin{array}{l}\text { 〈p〉 Señor Presidente, yo lamento que se prefiera felicitar a } \\
\text { Chávez, que colabora con los terroristas y tiene en su } \\
\text { Gobierno a dirigentes de ETA, como han hecho algunas } \\
\text { personas aquí, porque en mi caso y el de mi grupo, entre } \\
\text { Chávez y el juez de la Audiencia Nacional de un Estado de } \\
\text { Derecho, como es el señor Velasco, no tenemos dudas de que } \\
\text { apoyaremos al juez de la Audiencia Nacional. 〈/p〉 }\end{array}$ & EUROPARL & 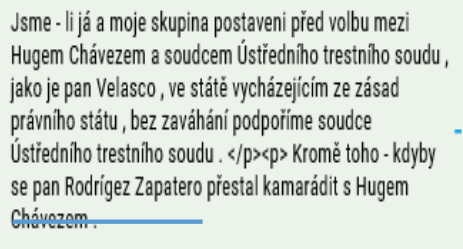 \\
\hline ב EUROPARL & $\begin{array}{l}\text { 〈p〉 Señor Presidente, un juez de la Audiencia Nacional } \\
\text { española ha confirmado lo que muchos ya sabiamos : que el } \\
\text { Presidente de Venezuela, Hugo Chávez, colabora con } \\
\text { terroristas de ETA y de las FARC. }\end{array}$ & EUROPARL & 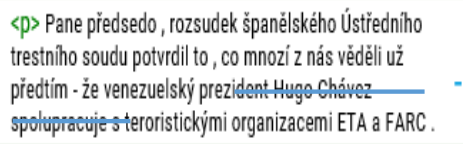 \\
\hline EEUROPARL & $\begin{array}{l}\text { 〈p〉 Señor Presidente, yo lamento que se prefiera felicitar a } \\
\text { Chávez, que colabora con los terroristas y tiene en su } \\
\text { Gobierno a dirigentes de ETA, como han hecho algunas } \\
\text { personas aquí, porque en mi caso y el de mi grupo, entre } \\
\text { Chávez y el juez de la Audiencia Nacional de un Estado de } \\
\text { Derecho, como es el señor Velasco, no tenemos dudas de que } \\
\text { apoyaremos al juez de la Audiencia Nacional. 〈/p〉 }\end{array}$ & EUROPARL & $\begin{array}{l}\text { Jsme - lijá a moje skupina postaveni preed volbu mezi } \\
\text { Hugem Chávezem a soudcem Ústreedniho trestního soudu, } \\
\text { jako je pan Velasco, ve státẻ vycházejicím ze zásad } \\
\text { právniho státu, bez zaváháni podporímo soudco } \\
\text { Ústredniho trestniho soudu . </p><p> Kromě toho - kdyby } \\
\text { se pan Rodrigez Zapatero prestal kamarádit s Hugem } \\
\text { Chávezem. }\end{array}$ \\
\hline
\end{tabular}

Debido a que en mi país no existe la misma división territorial, que admita a entidades territoriales inferiores cierta autonomía legislativa, la terminología que se suele utilizar para su denominación revela rasgos del típico comportamiento asimétrico y los traductores se enfrentan a una lista bastante larga de posibles traducciones de dicho concepto, o dicho en otras palabras "productos de diferentes técnicas de traducción": calco, sustitución, préstamo, etc. (Vinay y Darbelnet, 1958, en su modificación posterior de Dubský).

1.1.1. La realidad extralingüística muy diferente-equivalencia parcial o total

Ahora bien, a pesar de todo ello, hay, conceptos jurídicos que, aunque hacen referencia a una realidad extralingüística concebida de manera muy comparable (no digo idéntica), aun manifiestan una tendencia de cierta "inestabilidad terminológica". Esta inestabilidad terminológica 
nosotros la adjudicamos al grado de especialidad del texto traducido y del género textual dentro del cual empleamos los conceptos especializados (jurídicos, en nuestro caso).

Un ejemplo de lo que acabamos de presentar queremos ilustrarlo en la terminología empleada para denominar los tipos de delitos según el grado de intención del autor. El Código Penal español (igual que el checo) en su art. 5 dice que" No hay pena sin dolo o imprudencia" y consecuentemente en su art. 10 distingue entre los delitos dolosos e imprudentes ("Son delitos las acciones y omisiones dolosas o imprudentes penadas por la ley"1). El diccionario general checo de Dubský (Dubský et alii, 1996) ofrece para traducir el adjetivo correspondiente para un hecho "cometido con voluntad de hacerlo" (úmysIný, en checo) estos adjetivos: intencional, intencionado, deliberado, expreso, hecho intencionadamente/de propósito, premeditado, hecho con premeditación / a sabiendas. Los diccionarios especializados ya reducen la lista anterior a: delito intencional (Vavroušová, Obdržálková, 2015) y a: delito intencional, delito deliberado o delito doloso (Brynda, 2014):

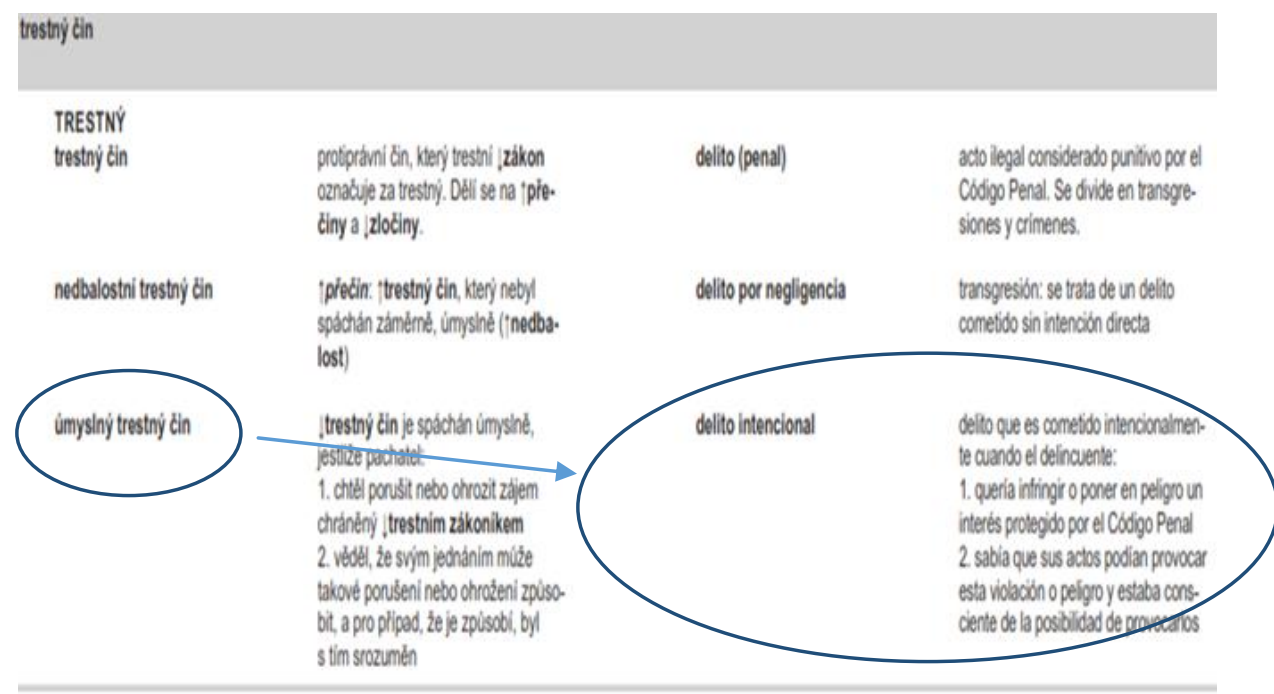

(Vavroušová, Obdržálková, 2015)

${ }^{1}$ Disponible en línea en:https://www.boe.es/buscar/act.php?id=BOE-A-1995-25444 [Fecha de consulta: 1 de mayo de 2015]. 
úmysiny intencional, intencionado; tresny tin deliberado, intencional,

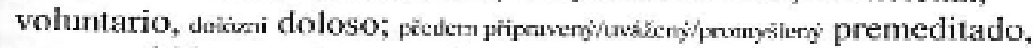
preconcebido, cn primer grado, preterintencional; >arméng deliberado, determinado

$$
\text { (Brynda, 2014) }
$$

La cuestión que se nos plantea en relación con esos adjetivos, y a cuya respuesta pretendemos dedicarnos a continuación, es: ¿hasta qué punto las soluciones que ofrecen los diccionarios checos-españoles para traducir el adjetivo checo úmyslný al español pueden ser consideradas como funcionales? ¿Son todos los adjetivos apropiados para ser utilizados en cualquier contexto? ¿Sería legítimo eliminar una de las dos variantes como menos apropiada? $\mathrm{O}$, al contrario, ¿se pueden utilizar todas indistintamente en cualquier situación?

La sinonimia existente entre la dicotomía intencional y doloso, se puede percibir, ante todo desde la perspectiva de los usuarios nativos no expertos en el ambiente jurídico e incluso desde la perspectiva del traductor como total. No obstante, consultando el Código Penal español vemos que el adjetivo intencional no aparece allí en forma de adjetivo, lo cual significa que en textos de alto grado de especialización esa variante probablemente no será la más adecuada. Un sencillo análisis del entorno contextual de doloso e intencional, realizado a base de datos del CREA, nos demuestra que ambas variantes no serán, evidentemente sinónimos absolutos (o estilísticamente equivalentes), ya que cada una prefiere utilizarse en otro entorno contextual. Es además, el adjetivo doloso el que aparenta supeditarse más a formar las colocaciones lexicales (palabras complejas) con otros términos jurídicos (omisión dolosa, homicidio doloso, delito doloso, muerte dolosa, conducta dolosa, cometer dolosamente), como evidencian los ejemplos que siguen: 
CONCORDANCIA

alor sobre la información y su autor, así como la intencionalidad del mismo, que en modo alguno puede $s$ ** noruego, ha cuestionado en su página editorial la intencionalidad y algunas de las afirmaciones conteni * planteó la medida en la anterior legislatura- la intencionalidad de la iniciativa por encontrarse "pri * urante la lectura de su informe, destacó la clara intencionalidad del asesino a la hora de golpear a Pi ** s. "Es una muestra más -señaló Paños- de la clara intencionalidad por parte del asesino que distingue $\mathrm{p}$ * aron a éste, si se llegara a probar que actuó con intencionalidad, están todavía claras. En los mismos * existencia de estas cajas no implica siempre una intencionalidad delictiva. El concepto genérico de ca * do el comportamiento del contribuyente ha estado "intencional y deliberadamente" dirigido a la defrauda ** Administración de Justicia, unida a la manifiesta intencionalidad y reiteración en la comisión de tales ** millón y medio de pesetas. La sentencia recoge la intencionalidad difamatoria del ministro y añade que * resión de que tras la pregunta subyace una cierta intencionalidad o una cierta acusación implícita resp * ha quedado demostrada su participación "directa e intencional" en operaciones de narcotráfico.

condenados como autores o cómplices de la muerte intencional del cónyuge de cualquiera de los contraye ** o a los siguientes criterios: a) La existencia de intencionalidad. b) Plazo de tiempo durante el que se ** sitio, sin que exista por su parte la más mínima intencionalidad, pese a lo cual pueden ser sancionado ** mas y que son los siguientes: a) La existencia de intencionalidad. b) Plazo de tiempo durante el que se ** los que intervenga dolo directo: debe existir la intencionalidad de dañar, robar secretos, estafar $0 \mathrm{c}$ ** tráfico de drogas sólo puede cometerse de manera intencional o dolosa; a diferencia de delitos como el ** en los beneficios o en las pérdidas y un elemento intencional: la "affectio societatis" o intención de ** itorio del Estado de acogida. Desde luego que fue intencionel gut tariamente; la intención: el refugiado debe haber intencionalmente realizado el acto por el cual sea re **

CONCORDANCIA

ión: Artículo 349 1. El que, por acción omisión dolosa, defraudare a la Hacienda pública estatal, aut ** igo serán aplicables al que, por acción (u omisión dolosa, defraudare a la Seguridad Social para eludir ** la documentación de cobertura de las invexeiones doledmente obtenidas por él". Portabella agregó que ** os reservados ha podido producirse una desviación dolosa de fondos públicos en concomitancia con hechos ** os reservados ha podido producirse una desviacion dolosa de fondos publicos en concomitancia con hechos $* *$ ma resolución de Salamanca, que descarta el ánimo doloso en el procesado -condenado anteriormente por $d * *$ delitos fiscales sólo se pueden cometer "en forma y no por imprudencia", de forma tal que "la co ** ganizar y dirigir una banda armada. Y la "omisión dolosa del procesado José Barrionuevo se convierte, * consumación y que el delito de robo coh homicidio doloso to es competencia del jurado. Tampoco serán co ** encia más rigurosa, de un parricidio imprudente o doloso, según el mayor o menor riesgo que supusiera e ** condenado a más de un año de cárcel por uf delito doloso.

incompatibilidad sobrevenida o condena poldelito doloso, Rhevia instrucción del correspondiente expedi ** tro años, sino que su comportamiento, además, fue doloso al adjudicar al demandante la paternidad a sab ** delito debe implicar necesariamente "un propósito doloso y preciso para su comisión; es decir, el ánimo ** adores, salvo que haya habido negligencia grave $\circ$ dolosa. e) Mantener informado al empresario sobre su ** condenados como autores o cómplices de la muerte dolosa del cónyuge de cualquiera de ellos. Este imped $* *$ encia de haber realizado un acto ilícito en forma dolosa o negligente; la responsabilidad penal -en el ** ntido amplio, la culpa abarca tanto las conductas dolosas como las culposas o negligentes). La responsa ** ogas sólo puede cometerse de manera intencional dolosa; a diferencia de delitos como el homicidio que ** ogas 3010 puede cometerse de manera intencional o dolosa; a diferencia de delitos como el homicidio que ** la culpa 0 imprudencia. Una acción (u omisión) es dolosa si se ha realizado en forma consciente y volun ** la culpa o imprudencia. Una acción (u omisión) es dolosa si se ha realizado en forma consciente y volun ** nados, dentro o fuera de España, por unf conducta dolosa que dpnstituya en nuestro país delito sanciona ** na superior a un año"; "haberlo sido ofr conducta dolosa", etcédera). Y las soluciones están integradas ** un año; c) haber sido condenado por un conducta dolosa; d) ghe constituya en España delito sancionad **

REAL ACADEMIA ESPAÑOLA: Banco de datos (CREA) [en línea]. Corpus de referencia del español actual. <http://www.rae.es>

Sin embargo, los ejemplos citados anteriormente contrastan con los resultados obtenidos tras consultar un banco de datos de textos traducidos - Intercorp, donde vemos muy bien que entre los adjetivos "intencional" y "doloso" es el primero (la variante que consideramos como no terminológica o estilísticamente neutral) el que prevalece en los textos especializados traducidos. En el corpus hemos encontrado, entre todos los textos traducidos solamente 4 ejemplos de la variante terminológica doloso frente a un número bastante alto de contextos donde el adjetivo checo úmyslný se traduce con el adjetivo intencional, el cual, teniendo en cuenta el léxico del 
Código Penal español y los resultados del análisis de CREA, consideramos como la variante estilísticamente neutral, no terminológica:

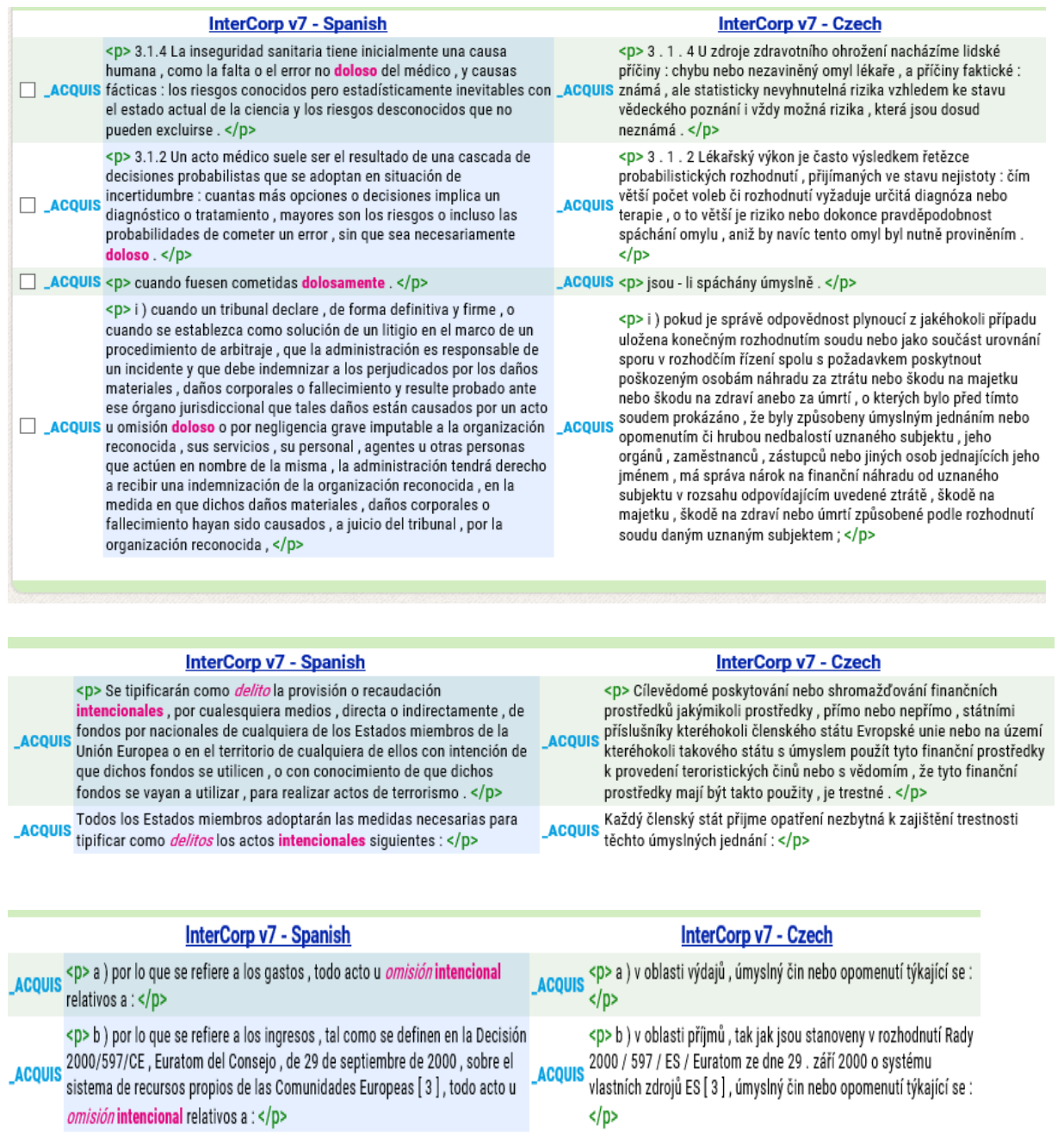

Hikma 14 (2015), 127-140 


\begin{tabular}{|c|c|}
\hline InterCorp v7 - Spanish & InterCorp v7 - Czech \\
\hline $\begin{array}{l}\text { La doctrina del doble efecto, bien entendida, no justifica lo que } \\
\text { hicieron los médicos, pero al acostumbrarlos a la práctica de } \\
\text { _Svortar la vida de los pacientes sin obtener consentimiento, parece } \\
\text { haber allanado el camino para el homicidio intencional. }\langle/ p\rangle\end{array}$ & 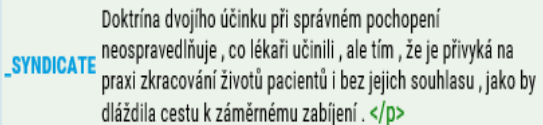 \\
\hline
\end{tabular}

Čermák, P. - Vavřín, M.: Korpus intercorp es, verze 6 z 8. 4. 2013.

Ústav Českého národního korpusu FF UK, Praha 2013. <http://www.korpus.cz>

\section{CONCLUSIONES}

¿Por qué sucede eso? Quizás este hecho pueda explicarse teniendo en cuenta que las bases de datos de textos jurídicos traducidos trabajan con los textos del derecho comunitario, donde el componente constante y el componente potencial no están distribuidos de la misma manera como en los textos del derecho nacional. La terminología jurídica utilizada en los textos del derecho comunitario es menos marcada estilísticamente, lo cual adjudicamos a la tendencia del lenguaje jurídico comunitario a no introducir en la terminología jurídica universal elementos idiosincrásicos de los derechos nacionales. Otra explicación de lo que acabamos de comentar la podemos encontrar en lo que, hasta cierto modo, ya afirmó, si bien no en relación con la traducción especializada, gran teórico checo de la traducción, Jiří Levý (traducido por Králová y Cuenca Drouhard, 2013: 110, lo subrayado es nuestro):

Resumiendo los problemas léxicos de la selección de método, cabe decir que los errores de traducción son productos de tres tipos de desviaciones:

a) Entre la denominación general y la específica.

b) Entre la denominación neutra y la expresiva.

c) Entre la repetición y la variación de los medios léxicos.

En general, los traductores suelen desviar las tendencias expresivas del original hacia uno de los polos mencionados; no obstante, conforme a la sicología del trasvase, se orientan más bien a la generalización, la neutralización y la repetición.

En cualquier caso, cabe plantearse la cuestión de si considerar esas desviaciones (intencional - doloso) como problemáticas y erróneas. Según mi opinión (y desde la perspectiva del usuario no nativo) se trata de diferentes técnicas de traducción (variantes). Aparte de otros motivos desde la insuficiente competencia del traductor hasta la obligación de usar la terminología única, una razón de por qué el traductor opta por una u otra variante, puede consistir en el efecto que el traductor espera que produzca. El traductor, aparte de tener en cuenta la finalidad del texto meta y el género 
textual dentro del cual se mueve, debería preguntarse por el efecto que se espera que produzca su traducción. Si el traductor de textos especializados, en vez de utilizar un adjetivo terminológico (sustituto terminológico de la misma realidad extralingüística en TO - delito doloso), opta por un equivalente, que consideramos, no terminológico (delito intencional), no consigue que el texto traducido sea incomprensible, sino que simplemente, debilitará la traducción lexicalmente. La traducción se percibe como lexicalmente "más pobre" y, por lo tanto, quizás menos eficaz, lo cual puede ser entendido como defectuoso en contextos de alto grado de especialización (por ejemplo a la hora de verse obligado a traducir al castellano las disposiciones del Código Penal checo, lo cual es muy corriente en la traducción de las sentencias o comisiones rogatorias checas). Es en los contextos especializados, donde, por añadidura, el empleo de conceptos no terminológicos puede alterar la relación necesaria entre el componente constante y componente potencial, ya que la presencia del componente constante se verá disminuida a favor del léxico general (común), lo cual hace debilitar el valor estilístico del TM. Sin embargo, tal debilitamiento del valor estilístico de la traducción se puede considerar como admisible en contextos jurídicos (géneros textuales) de menos grado de especialidad (noticias de prensa), donde a menudo somos testigos del uso sinonímico de conceptos jurídicos que se diferencian entre sí o estilísticamente (intencional - doloso) o incluso de contenido, al ser empleados como términos jurídicos (acusado - imputado).

REFERENCIAS BIBLIOGRÁFICAS:

AlcARAZ VARÓ, Enrique; Hughes, Brian, El español jurídico. Barcelona: Ariel, 2002.

AlCARAZ VARÓ, Enrique, "Anisomorfismo y lexicografía técnica". En: González L. y Hernúñez P. (ed.), Las palabras del traductor. Bruselas: Es Letra, 2004, pp. 201-220.

Čermák, P.; VAVŘín, M., Korpus intercorp_es, verze 6 z 8. 4. 2013. Ústav Českého národního korpusu FF UK. Praha, 2013.

Disponible en línea en: http://www.korpus.cz

[Fecha de consulta: 26 de abril de 2015].

BRYNDA, Jiří, Česko-španělský právnický a ekonomický slovník / Diccionario jurídico y económico checo - español, A-O, P-Ž. Brno: Tribun EU, 2013.

DUBSKÝ, Josef, "El valor explícito de las construcciones verbales y verbonominales del español". En: Español Actual, 1984, pp.13-20.

-, "Aspectos lingüísticos de las cartas comerciales". En: Volumen preparado por José Polo. Madrid: Coloquio, 1984. 
—, Josef,Základy španělské lexikologie pro překladatele a tlumočníky. Praha: Státní pedagogické nakladatelství, 1989.

—, Josef, Velký česko-španělský slovník I-II, Praha: Leda, Academia, 1996.

KRÁlovÁ, J.; CUENCA DROUHARD, M. J., Jiř́ Levý: Una concepción (re)descubierta. Vertere, Monográficos de la revista Herméneus, 15, 2013.

Real Academia Española: Banco de datos (CORPES XXI) [en línea]. Corpus del español del siglo XXI. <http://www.rae.es> [Fecha de consulta: 12 de julio de 2015].

Vavroušová, Petra; ObdržÁlková, Vanda, Márquez Bobadilla, Mónica, Česko-španělský slovník pro interkulturní práci - Diccionario checoespanol: trabajo intercultural. Praha: In Báze, 2014.

Disponible en línea en:

http://www.icpraha.com/theme/lcp/files/interkulturni prace spanelstin a.pdf [Fecha de consulta: 28 de abril de 2015]. 